\title{
DIAGNOSIS OF URINARY INFECTION
}

\section{COMPARISON OF A POUR-PLATE COUNTING METHOD WITH A ROUTINE METHOD}

BY

\author{
DENNIS GUTTMANN, M.A., B.M., B.Ch., B.Sc. \\ M.R.C.P. \\ Medical Registrar, University College Hospital, London
}

The assessment of the results of bacteriological examination of the urine is of primary importance in the study of urinary infections, and may be difficult in a number of situations. Evidence has accumulated that many infections of the urinary tract may be asymptomatic, and the detection of these represents one such problem. Post-mortem studies often reveal evidence of active or healed renal infections in patients who had no urinary symptoms during life, and several such studies have shown that pyelonephritis was diagnosed before death in only 20 to $30 \%$ of the cases in which it was demonstrated at necropsy. Patients also present with advanced renal failure or severe hypertension attributable to chronic pyelonephritis which had previously not been clinically manifest. Efforts are being directed towards the early detection of this condition, before irreversible secondary effects have become established, and various methods have been investigated for use as screening tests for the examination of urine specimens. A further problem frequently encountered is the differentiation between contamination and true infection of the urine specimen. The danger of introducing infection into the urinary tract during catheterization is sufficiently well recognized to make this procedure undesirable as a routine diagnostic method. The use of clean voided specimens, especially from women, may, however, increase the risk of contamination of the specimen with perineal commensals.

The usual qualitative bacteriological methods of urine examination suffer from certain limitations, and quantitative methods of urine culture have been introduced in an effort to increase the precision of such investigations. Marple (1941) applied the pour-plate technique to the examination of urine specimens, and this method has been used since then by other workers (Kass, 1955, 1956, 1957 ; Sanford et al., 1956 ; Kaitz and Williams, 1960). These workers claim that by the use of such techniques "significant bacteriuria" may be differentiated from contamination of the urine specimen, and that subclinical infections may be recognized when other bacteriological methods fail to reveal them. Kass (1960) reviewed the results obtained by the pour-plate technique, and concluded that asymptomatic bacteriuria is a frequent and important finding and is significantly associated with infection of the urinary tract. Kaitz and Hodder (1961) wrote: "At the present time there is no short cut to the detection of bacteriuria other than quantitative urine culture performed by one method or another."

Kass (1955) suggested that by the use of his method counts of less than 10,000 bacteria per $\mathrm{ml}$. of urine may be ascribed to contamination, whereas counts of more than 100,0000 organisms per ml. imply infection of the urinary tract. He has, however, listed a number of situations in which counts below 100,000 may be obtained in the presence of active urinary infection. Counts between 10,000 and 100,000 were obtained infrequently, and on repetition generally fell below or above these limits. Clean voided mid-stream specimens were
E. JOAN STOKES, F.R.C.P.

Clinical Bacteriologist, University College Hospital, London

used from males, and catheter specimens from females. Kass (1956) showed that the use of carefully collected clean voided specimens in women gave results comparable with catheter specimens, and that urine specimens could be stored for one hour at room temperature or up to 48 hours under refrigeration without significant change in the count. Sanford et al. (1956) suggested that more than 1,000 organisms per $\mathrm{ml}$. of urine obtained by catheterization are required for a diagnosis of infection. Merritt and Sanford (1958) placed the lower limits of "significant bacteriuria" at 10,000 organisms per $\mathrm{ml}$. in catheter specimens and 50,000 per $\mathrm{ml}$. in clean voided specimens.

In view of the laboriousness of the pour-plate method, a number of authors have investigated simpler methods by which quantitative results of similar significance might be obtained. O'Sullivan et al. (1960) used a standard platinum loop of $3 \mathrm{~mm}$. internal diameter for surface inoculation of agar plates with undiluted urine. and compared colony counts thus obtained with those of a pour-plate method similar to that of Kass. Mou and Feldman (1961) also compared a number of quantitative methods, including surface inoculation of agar plates with standard loopfuls of urine. These authors suggest that this method can provide information comparable with that of more elaborate quantitative techniques such as the pour-plate method. Grace Turner (1961) used a method of surface inoculation of selective media with $0.01 \mathrm{ml}$. of undiluted urine delivered from specially drawn sterile pipettes. With this method, however, 1,000 colonies will be grown per plate from a urine containing 100,000 organisms per $\mathrm{ml}$., so that time saved in the preparation of dilutions of the urine may be lost in the counting of colonies after incubation.

The present investigation was undertaken to discover whether the pour-plate technique would provide valuable additional information when compared with the semiquantitative method already in use at University College Hospital. Previous accounts of simple quantitative methods have been reported without reference to clinical findings, assuming that a count of 100,000 bacteria per $\mathrm{ml}$. of urine as shown by the pour-plate method is significant. It is not reasonable to assume this without clinical follow-up unless the pour-plate and urine-collection methods employed are those of Kass. The significance of our results was therefore assessed by a three-months follow-up of case records to discover whether there was clinical evidence of infection at the time of urine examination.

\section{Methods}

One hundred clean voided urine specimens sent to the laboratory for bacteriological examination were taken at random and subjected to examination by the pourplate technique and the routine method. The standard procedure at this hospital for the collection of specimens from female patients comprises washing of the vulva and perineum with soap and water, drying with a clean towel, and collecting a mid-stream "clean catch" 
sample. The nursing staff are instructed to send the urine specimens to the laboratory within one hour of collection or, where this is impracticable, refrigerate them.

On arrival in the laboratory the urine is refrigerated. As soon as convenient the specimen is well mixed and about $5 \mathrm{ml}$. is removed under sterile precautions into a sterile 3 by $\frac{1}{2}$ in. (7.5 by $1.3 \mathrm{~cm}$.) stoppered tube and either cultured immediately or again refrigerated. For domestic convenience the remainder of the specimen is sent to another room, where a wet preparation of the deposit is examined and chemical tests are made. All urines showing more than three pus cells per one-sixth field in the deposit are cultured from the refrigerated aliquot. Samples showing fewer cells than this are not cultured unless a special request has been made. When the specimen was to be examined by the pour-plate technique also, urine was taken from the refrigerated tubes within two hours of the same sample being submitted to the routine procedure, the tube being refrigerated meanwhile.

\section{Pour-plate Technique}

Pour plates were made in five sterile disposable Petri dishes from each urine sample as follows: One plate contained $0.5 \mathrm{ml}$. of undiluted urine, two plates each contained $0.1 \mathrm{ml}$. of undiluted urine, and two plates each contained $0.1 \mathrm{ml}$. of 1 in 100 dilution of urine in sterile nutrient broth. Approximately $10 \mathrm{ml}$. of autoclaved nutrient agar, cooled to $50^{\circ} \mathrm{C}$., was added to each dish, which was then agitated to ensure even distribution of the urine sample in the agar. Colonies were counted with the aid of a hand lens after 24 hours' incubation. Up to 600 colonies could be readily counted on one plate; however, if inspection showed that more than about 500 colonies had grown only half the plate was counted. Counts up to one million organisms per ml. of urine were recorded as such ; counts in excess of this number were recorded as "more than one million." Each result was the average of counts on two plates, which in general agreed to within $50 \%$.

\section{Routine Method}

The refrigerated urine is well mixed and a 5-mm. loopful (external diameter), delivering approximately $0.006 \mathrm{ml}$., is seeded on to each of three plates, one containing blood agar and one MacConkey agar for identification, and the third blood agar for sensitivity tests. Half plates are used for each specimen for identification, and the pool of inoculum, covering about a quarter of the available area, is spread out to obtain single colonies in the usual way. A whole plate heavily seeded is employed for the sensitivity test (Stokes, 1960). The blood agar is incubated anaerobically; the MacConkey agar and sensitivity plate are incubated in air. Anaerobic incubation is not essential but has two advantages: first, that occasional anaerobic infections are diagnosed without delay; and, second, that since many vaginal organisms grow better in this atmosphere contamination is sometimes apparent when the aerobic culture is pure. All cultures are examined and a report is made after overnight incubation. Sometimes a second report of final identification or on further sensitivity tests is required on the second day. All negative anaerobic plate cultures are reincubated, but no further report is sent unless significant growth appears. The remainder of the refrigerated urine is centrifuged, the supernatant is discarded, and a Gram-stained film of the deposit is examined with the cultures. This is essential in many cases for estimating the significance of culture results.

Results are recorded in the following terms:

Group A : "Culture sterile after 24 hours." This report is made if at least two out of the three plates showed no growth after 24 hours and no organisms were seen in the smear.

Group B: "No significant growth." In this case a mixed growth of fewer than 50 colonies were grown per plate, with no particular organism predominating, and only very occasional organisms or none were seen in the smear.

Group C: "Growth of doubtful clinical significance"; 50 to 100 organisms or more were grown per plate, of mixed colonial type. When a particular organism predominated it would be reported in addition, provided it was also seen in large numbers in the smear associated with pus cells.

Group D: "Cultures yielded ... sensitive to ...." (the appropriate organism or organisms and antibiotics being inserted). This indicates that more than 50 colonies were seen on each of three cultures and were all of one colonial type (or more than 50 each of two types), and that there was no evidence of contamination in the smear. This is taken as clear laboratory evidence of infection. Sensitivity test results on contaminating organisms are never reported.

All cultures were reported by Dr. F. C. Stallybrass before the pour-plate results had been obtained.

\section{Results}

Results obtained from patients without and with clinically active urinary infections (as judged from scrutiny of the case record) are presented separately in the Table. In the clinically uninfected group three specimens were found to contain more than 100,000 organisms per ml., the figure regarded by Kass as indicative of significant bacteriuria. These specimens, reported by the routine method either as sterile (one) or showing no significant growth (two specimens), were

\begin{tabular}{|c|c|c|c|c|c|c|}
\hline \multirow{2}{*}{\multicolumn{2}{|c|}{$\begin{array}{l}\text { No. of } \\
\text { Organisms } \\
\text { per ml. }\end{array}$}} & \multicolumn{4}{|c|}{ Group } & \multirow{2}{*}{ Total } \\
\hline & & $\mathbf{A}$ & B & C & $\mathbf{D}$ & \\
\hline \multicolumn{7}{|c|}{ Not Clinically Infected } \\
\hline $\begin{array}{l}0-10,000 \\
10,000-100,000 \\
\text { Over } 100,000\end{array}$ & $\begin{array}{l}\cdots \\
\cdots \\
\cdots\end{array}$ & $\begin{array}{r}31 \\
4 \\
1\end{array}$ & $\begin{array}{r}18 \\
10 \\
2\end{array}$ & $\begin{array}{l}1 \\
2 \\
0\end{array}$ & $\begin{array}{l}0 \\
0 \\
0\end{array}$ & $\begin{array}{r}50 \\
16 \\
3\end{array}$ \\
\hline Total & . & 36 & 30 & 3 & 0 & 69 \\
\hline \multicolumn{7}{|c|}{ Clinically Infected } \\
\hline $\begin{array}{l}0-10,000 \\
10,000-100,000 \\
\text { Over } 100,000\end{array}$ & $\begin{array}{l}\cdots \\
\cdots\end{array}$ & $\begin{array}{l}0 \\
0 \\
0\end{array}$ & $\begin{array}{l}1 \\
2 \\
0\end{array}$ & $\begin{array}{l}0 \\
1 \\
3\end{array}$ & $\begin{array}{r}1 \\
2 \\
21\end{array}$ & $\begin{array}{r}2 \\
5 \\
24\end{array}$ \\
\hline Total & . & 0 & 3 & 4 & 24 & 31 \\
\hline
\end{tabular}

all from women without urinary symptoms. The organisms isolated were a diphtheroid, a lactobacillus, and a haemolytic streptococcus, the latter also being obtained from a high vaginal swab from the same patient. It seems likely that these specimens were contaminated with vaginal secretions.

Of the 31 specimens in the clinically infected group, 24 were found to contain more than 100,000 organisms per $\mathrm{ml}$. Of these, 21 specimens were reported positive (group D) by the routine method, as were three other specimens in which the count showed a smaller number of organisms. Two specimens in the clinically infected group were found to contain fewer than 10,000 organisms per $\mathrm{ml}$. One of these, reported by the routine method as showing no significant growth, came from 
a woman with symptoms and signs of acute pyelonephritis, from whose urine Escherichia coli was subsequently isolated. The other specimen came from a man with stricture of the urethra, bladder diverticula, and large residual urine who had symptoms of dysuria at the time. Routine culture of the specimen yielded a heavy growth of a diphtheroid organism, which in view of the above findings, together with heavy pyuria, was considered to be of pathogenic significance in this case.

Five specimens in the clinically infected group were found to contain between 10,000 and 100,000 organisms per $\mathrm{ml}$. Two of these were reported as showing no significant growth. Both of these specimens came from patients who were under treatment with sulphonamides at the time that the specimens were obtained. One specimen, in which 85,000 organisms per $\mathrm{ml}$. were counted, was reported as showing a mixed growth of coliform organisms, the significance of which was doubtful; the patient was at the time being treated with penicillin and streptomycin for a pyrexia following caesarean section. Two specimens, containing between 10,000 and 100,000 organisms per ml., were considered to be significantly infected by the routine method. One, containing 32,000 organisms per $\mathrm{ml}$., was reported as yielding a small but pure growth of $E$. coli, and came from a patient in whom a clinical diagnosis of acute pyelonephritis had been made. The other, containing 45,000 organisms per ml., yielded a proteus. This specimen was obtained from a patient with a urinary infection following a gynaecological operation, who was receiving a course of tetracycline at the time that the specimen was obtained.

In Fig. 1 the same results are portrayed graphically, the actual counts obtained being displayed on a logarithmic scale. They demonstrate the broad general agreement obtained between the pour-plate and the routine method.

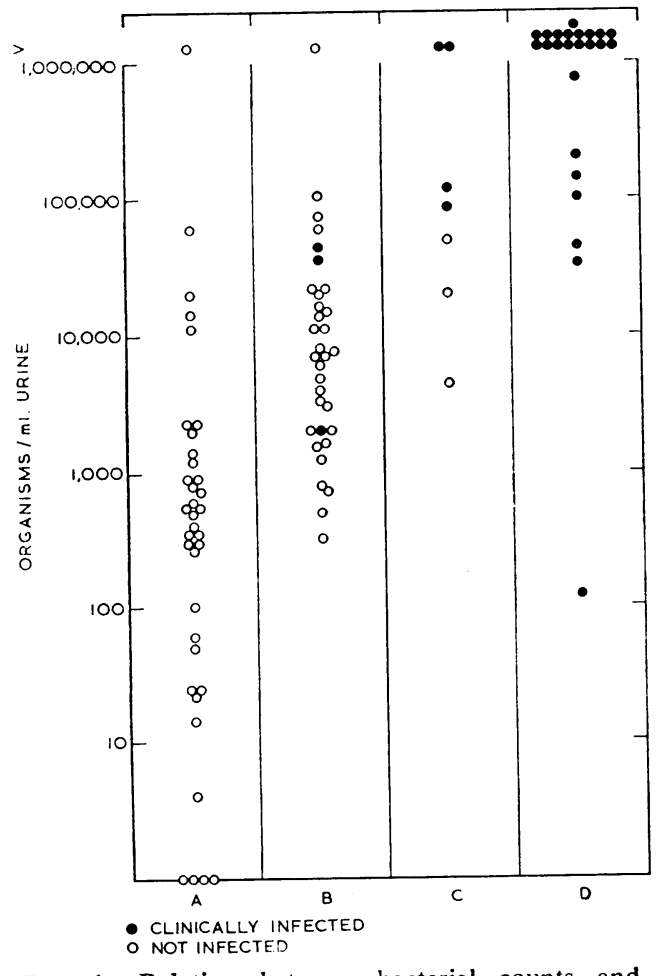

Fig. 1.-Relation between bacterial counts and routine reports. For group indications see text.
Thirty of the pour-plate cultures yielding some growth at 24 hours were reincubated and counted again at 48 hours; results are shown in Fig. 2. It will be seen that inconstant but, in some cases, considerable increases in the number of visible colonies took place after a further 24 hours' incubation, in one case a thirtyfold increase being recorded. This contrasts with the experience of some other workers-for example, King (1961)-who found no significant increase in counts when plates were incubated for a further 24 hours. Criteria of " significant bacteriuria" established by Kass (1955) counting after 24 hours, and Kaitz and Williams (1960), will not necessarily hold for modifications of this technique.

\section{Discussion}

Quantitative methods of urine culture have been introduced, and are more commonly employed, by American workers. This could be due to routine methods used in that country which would tend to give a heavy growth of any contaminating organisms present. For example, comparatively large quantities of

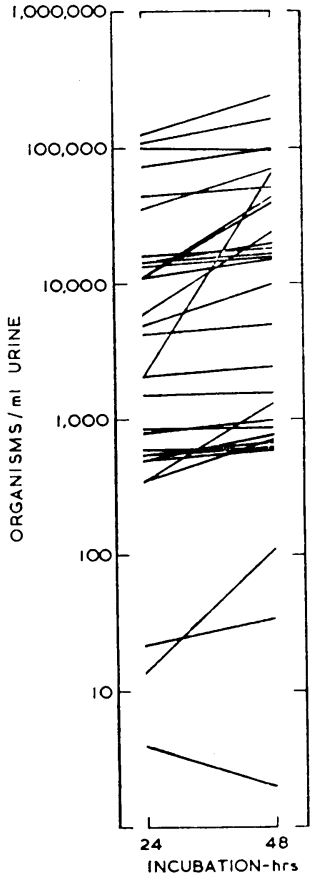

Fig. 2-Colony counts by pour-plate method. undiluted urine or the centrifuged deposit are cultured. Thus King (1961) inoculates slopes with about $0.2 \mathrm{ml}$. of undiluted urine ; Sanford et al. (1956) plate out loopfuls of the centrifuged deposit on selective media and also inoculate broth with loopfuls of deposit, subsequently isolating organisms by subculture. Many of the common perineal commensals are also important urinary pathogens, and by the use of these techniques may be recovered in heavy growth which bears no relation to their clinical significance in the specimen being examined. In these circumstances, additional quantitative methods of urine examination are helpful in the clinical interpretation of the bacteriological investigations.

The use of a semiquantitative routine method such as the one described avoids these difficulties to a great extent, provided that the culture plates are examined by a trained bacteriologist who appreciates the medical aspects of the problem. On the other hand, uncritical acceptance of quantitative results obtained by the pour-plate method may also lead to errors. Thus the present series includes three cases in which the pour-plate revealed over 100,000 organisms per $\mathrm{ml}$. of urine in the absence of an infection of the urinary tract, as judged by the routine method and the clinical findings, and presumably attributable to faulty technique in the collection of specimens. On the other hand, negative and equivocal results were obtained in a number of cases where there was clinical evidence of a urinary infection, in some of which the routine semiquantitative method yielded a positive result. In some instances these anomalous findings could be explained on the basis of the chemotherapy which the patients were receiving. In the last analysis, however, the interpretation of lahoratory results must always be made by the clinician, who 
can correlate these with the clinical findings. It may be argued that a bacteriological report which deliberately admits the presence of doubt in the significance of the culture results is less liable to bias the clinical observer than a strictly quantitative assessment in terms of a set of figures which may give a spurious impression of accuracy and which, in any case, may in certain circumstances be unreliable (Kass, 1955).

The present series, contrary to the results reported by other workers, contains a substantial proportion of cases in which counts between 10,000 and 100,000 organisms per ml. were obtained. In part this could be explained by the fact that the urine specimens submitted for culture were selected on the basis of the microscopy of the deposit as explained above. It is also possible that deficiencies in the technique of collection and storage of the specimens were partly responsible. This does not, however, appreciably affect the findings of this investigation, which was not designed to survey an unselected series of patients or to assess the incidence and significance of asymptomatic bacteriuria, but to compare the pour-plate technique with the method already in use at this hospital.

We do not feel that the pour-plate technique is reliably capable of demonstrating the presence of "significant bacteriuria" in cases where the semiquantitative method here described fails to reveal infection of the urine. None of the specimens in the clinically infected group in which over 100,000 organisms per ml. of urine were demonstrated by the pour-plate method was reported as "sterile" or showing " no significant growth," and Fig. 1 shows the good general agreement between the two methods. Identification cultures and smear examination are in any case essential, and there- fore we do not think that the extra labour involved in setting up pour plates is justified by an increased sensitivity in the detection of subclinical infections of the urinary tract. We also think that this extra labour limits its usefulness as a screening procedure for the examination of large numbers of urine specimens. It is suggested that a simpler method, such as the one of Turner (1961) modified to yield less heavy growth, may be more appropriate for this purpose.

\section{Summary}

One hundred clean voided urine specimens were examined in parallel by the pour-plate counting method and by a routine semiquantitative method. There was close agreement between the two methods.

Subsequent evaluation of the reports by clinical follow-up for three months demonstrated no worth-while advantage for the extra labour involved in plate-pouring.

\section{REFERENCES}

Kaitz, A. L., and Hodder, E. W. (1961). New Engl. J. Med., 265, 667 .

and Williams, E. J. (1960). Ibid., 262, 425

Kass, E. H. (1955). Amer. J. Med., 18, 764.

Kass, (1956). Trans. Ass. Amer. Phyns, 69, 56

(1957). Arch. intern. Med., 100, 709.

(1960). In Biology of Pyelonephritis, edited by E. L. Quinn

King, J. W. (1961). Amer. J. clin. Path., 36, 60.

Marple, C. D. (1941). Ann. intern. Med., 14, 222.

Merritt, A. D., and Sanford, J. P. (1958). J. Lab. cltn. Med., $52,463$. Mou, T. W., and Feldman, H. A. (1961). Amer. J. clin. Path.,

O'Sullivan, D. J., FitzGerald, M. G., Meynell, M. J., and Malins, J. M. (1960). J. clin. Path., 13, 527.

Sanford, J. P., Favour, C. B., MaO, F. H., and Harrison, J. H. (1956). Ämer. J. Med., 20, 88.

Stokes, E. J. (1960). Clinical Bacteriology. Arnold, London.

Stokes, E. J. (1960). Clinical Bacteriol
Turner, G. C. (1961). Lancet, 2, 1062.

\title{
USE OF "SYNTOMETRINE" IN PREVENTION OF POST-PARTUM HAEMORRHAGE
}

\author{
BY \\ M. P. EMBREY, M.D., F.R.C.S.Ed.
F.R.C.O.G. \\ D. T. C. BARBER, M.B., B.S., F.R.C.S.Ed. \\ J. H. SCUDAMORE, M.B., Ch.B., M.R.C.O.G.
}

Nuffield Department of Obstetrics and Gynaecology, University of Oxford

The traditional conservative attitude to the management of the third stage of labour is changing. With the realization that it materially reduces the incidence of post-partum haemorrhage, the routine administration of an oxytocic with the birth of the head or anterior shoulder is becoming increasingly common and no longer has to be justified. Discussion nowadays centres on the particular type of injection most suitable for routine use. Obstetricians commonly inject ergometrine intravenously, as advised by Davis (1940), Lister (1950), and Martin and Dumoulin (1953). But for routine use by midwives, or when intravenous injection is not possible, ergometrine intramuscularly, with or without hyaluronidase, has been advocated (Flew, 1947 ; Daley, 1951 ; Kimbell, 1954 ; Dutton, 1958).

Fostered by the availability of the pure synthetic hormone, the newest phase in the prophylaxis of postpartum haemorrhage has seen a return to the posterior pituitary hormone oxytocin. Oxytocin has the disadvantage that its duration of action is shorter than that of ergometrine, so that delayed haemorrhage is more likely, but it acts more quickly than ergometrine by intramuscular injection. For routine use, therefore, the two drugs might with advantage be combined. Recently a stable solution containing oxytocin 5 units and ergometrine $0.5 \mathrm{mg}$. has been produced ("syntometrine"). It aims, combine in a single ampoule ready for immediate injection the rapid action of oxytocin with the more sustained action of ergometrine.

In a recent tocographic study (Embrey, 1961) the speeds of action of syntometrine and the ergometrine preparations were compared; syntometrine was revealed as the best substitute for intravenous ergometrine, suggesting that it might be commended for use when intravenous therapy is impracticable. We determined, therefore, to submit syntometrine to clinical trial, comparing its effectiveness in preventing post-partum haemorrhage with that of intramuscular ergometrine, the use of which had been routine practice in this department. 